\title{
Investigation on the Electrical Discharge Characteristics of a Unipolar Corona-Wire Aerosol Charger
}

\author{
Panich Intra ${ }^{\dagger}$, Artit Yawootti*, Usanee Vinitketkumnuen** and Nakorn Tippayawong***
}

\begin{abstract}
In the present study, a simple corona-wire charger for unipolar diffusion charging of aerosol particles is designed, constructed, and characterized. Experimental characterizations of the electrostatic discharge in terms of current-voltage relationships of positive and negative coronas of the corona-wire charger are also presented and discussed. The charging current and ion concentration in the charging zone increased monotonically with corona voltage. The negative corona showed higher current than the positive corona. At the same corona voltages, the current in the discharge zone is about 600 times larger than the charging current. The ion number concentrations ranged within approximately $5.0 \times 10^{10}$ to $1.24 \times 10^{16}$ and $4.5 \times 10^{12}$ to $2 \times 10^{16}$ ions $/ \mathrm{m}^{3}$ in the discharge and charging zones, respectively. A numerical model is used to predict the behavior of the electric potential lines. Numerical results of ion penetration through the inner electrode are in good agreement with the experimental results.
\end{abstract}

Keywords: Aerosol, Charger, Unipolar charging, Corona discharge

\section{Introduction}

Particle charging is an important process in electrical aerosol spectrometry. The process aims to impose a known net charge distribution on the aerosol particles for each size. Diffusion charging is the most commonly used mechanism for charging particles in electrical measurement instruments. In general, particles are allowed to collide with ions, and the charge carried by the ions is transferred to the particles. Unipolar diffusion charging has advantages over bipolar diffusion charging because the former does not reach an equilibrium charge distribution, thus attaining a higher charging efficiency [1]. Intra and Tippayawong have offered an overview of the current development status of available unipolar aerosol chargers based on corona discharge technique for airborne particles [1]. The main purpose of these chargers is to efficiently charge ultrafine particles with minimal losses. However, the loss of charged particles due to electrostatic and/or space charge effects is often severe and must be addressed in the development of unipolar chargers. Particle losses inside the chargers may be reduced in several ways, including (1) the application of a sinusoidal or square wave voltage to the electrode [2-4],

$\dagger$ Corresponding Author: College of Integrated Science and Technology, Rajamangala University of Technology Lanna, Chiang Mai, Thailand. (panich_intra@yahoo.com)

* College of Integrated Science and Technology, Rajamangala University of Technology Lanna, Chiang Mai, Thailand.

** Department of Biochemistry, Faculty of Medicine, Chiang Mai University, Chiang Mai, Thailand. (uvinitke@mail.med.cmu.ac.th)

*** Department of Mechanical Engineering, Faculty of Engineering, Chiang Mai University, Chiang Mai 50200 Thailand. (n.tippayawong@yahoo.com)

Received: May 25, 2010; Accepted: March 29, 2011
(2) the use of a turbulent jet of unipolar ions in a mixing chamber [5-7], and (3) introduction of surrounding sheath air flows at the boundary between the aerosol stream and the wall; this last step allows more space for the charged particles to flow through the charger without precipitating on the charger walls $[2,4,8]$. However, the application of a large sheath gas flow can result in aerosol dilution, which is not always desirable. Several charger designs can be complex.

In the current paper, a simple corona-wire charger for unipolar diffusion charging of aerosol particles is designed, constructed, and tested. The electrostatic discharge characteristics are experimentally investigated and discussed. A numerical model is also developed to obtain a better understanding on the charger operation. This is done by providing estimations of the ion penetration through the perforated inner electrode of the charger.

\section{Materials and Methods}

\subsection{Unipolar Corona-Wire Charger}

A corona-wire aerosol charger was used (Fig. 1). The design principle was similar to that of the cylindrical triode charger used by Hewitt [9], Liu and Pui [8], Buscher et al. [2], Lee et al. [10], and Biskos et al. [4]. Nonetheless, the present charger had collective differences from these existing chargers. The differences were as follows: (i) the concept of the present charger was simple, compact, and inexpensive, in which a short column charger was used to reduce diffusion and space charge loss of particles inside 
the charger; (ii) the present charger did not use sheath gas flow and aerosol dilution; and (iii) the dimensions, geometries, and arrangement of the charger in the present work were obtained such that appropriate electric field distribution inside the charger can be achieved as derived from the Poisson's equations. The proposed charger consisted of two concentric electrodes with a corona-wire placed along the axis. The outer electrode was made of stainless steel tube, $35 \mathrm{~mm}$ in diameter and $65 \mathrm{~mm}$ in length. The inner electrode was made of stainless steel tube, $21 \mathrm{~mm}$ in diameter and $50 \mathrm{~mm}$ in length. Thus, the gap between the inner and outer electrodes was $7 \mathrm{~mm}$. A 300 $\mu \mathrm{m}$ stainless steel wire maintained at a high voltage was used to produce the corona discharge, while the generated ions migrated to the inner electrode due to the high electric field in the region. A section of the inner electrode was made of a metal mesh to allow ions to flow in the charging zone. The metal mesh prevented the expansion of the aerosol flow into the corona discharge zone. The inner electrode collected most of the ions produced by a high voltage application. However, some ions were forced through the screen opening on the inner cylinder, which was grounded or driven voltage. The width of the screen opening on the inner cylinder was $20 \mathrm{~mm}$. The bottom and top of the charger discharge zone were composed of isolating material. Thus, the aerosol particles flowing in this annular gap region were exposed to unipolar ions and became electrically charged.

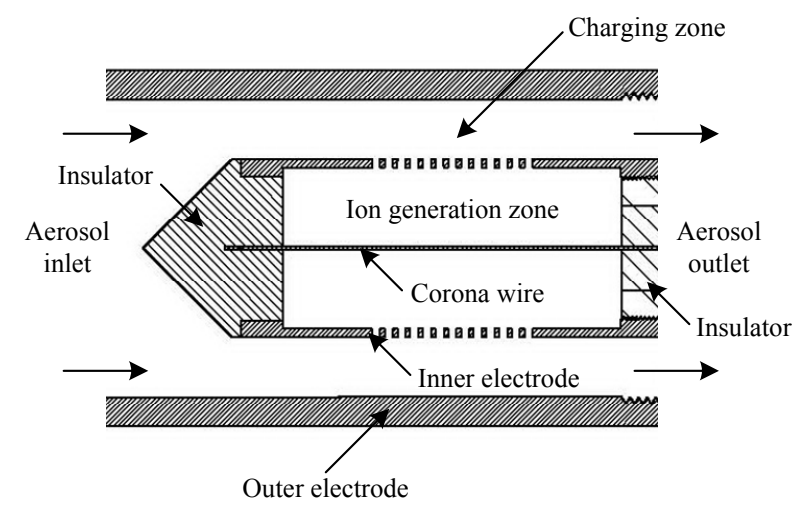

Fig. 1. Schematic diagram of the corona-wire aerosol charger.

\subsection{Numerical Model}

A numerical model was developed to gain a better understanding of the charger operation. Using this model, we investigated the distribution of electric field in the two main regions of the charger, after which we estimated the ion penetration through the screen opening on the inner electrode.

The commercial computational fluid dynamic software package CFDRC ${ }^{\mathrm{TM}}$ was employed in this work [11]. This software is based on the finite volume method; the model

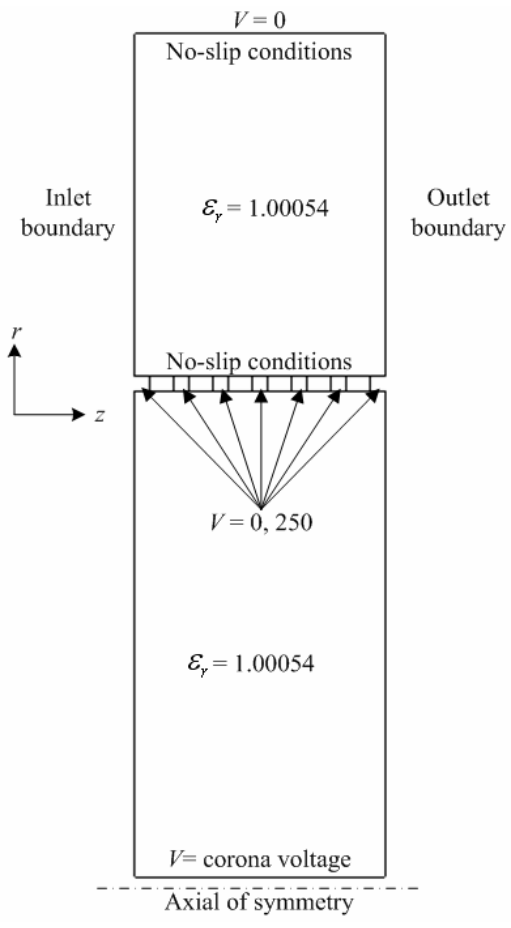

Fig. 2. Numerical domain for electric field calculation.

consists of Laplace's equation in the 2D, axisymmetric, and cylindrical coordinates for the present charger configurations. The numerical domain for electric field calculation is shown in Fig. 2. With respect to the boundary conditions used, constant potentials were applied to the corona-wire electrode $(0-10 \mathrm{kV})$ as well as the inner electrode $(0-250 \mathrm{~V})$. The space charge effect was assumed to be negligible. The operating gas density was 1.225 $\mathrm{kg} / \mathrm{m}^{3}$, and permittivity constant was 1.00054 . The zero gradient condition was applied to the boundaries without walls.

\subsection{Experimental System}

The schematic diagram for the electrostatic discharge characterization of the corona-wire aerosol charger is shown in Fig. 3. A commercial, adjustable DC high voltage power supply (Leybold Didactic Model 521721) was used to maintain the positive or negative high voltage difference in the charger, generally in the range of $0-10 \mathrm{kV}$. The discharge and charging currents from the inner and outer electrodes were measured directly with a Keithley 6517A electrometer incorporating a Keithley 6522 scanner card. The sensitive ammeter used was a Keithley 6517A electrometer, which had a special low current input amplifier. The input bias current was $<3$ fA and only 0.75 fA p-p noise $<20 \mu \mathrm{V}$ burden voltage on the lowest range, with the current measurement range of $1 \mathrm{fA}$ to $20 \mathrm{~mA}$. The rates of discharging and charging are generally proportional to the mean ion number concentration in the discharge and charging zones of the charger. Let us 


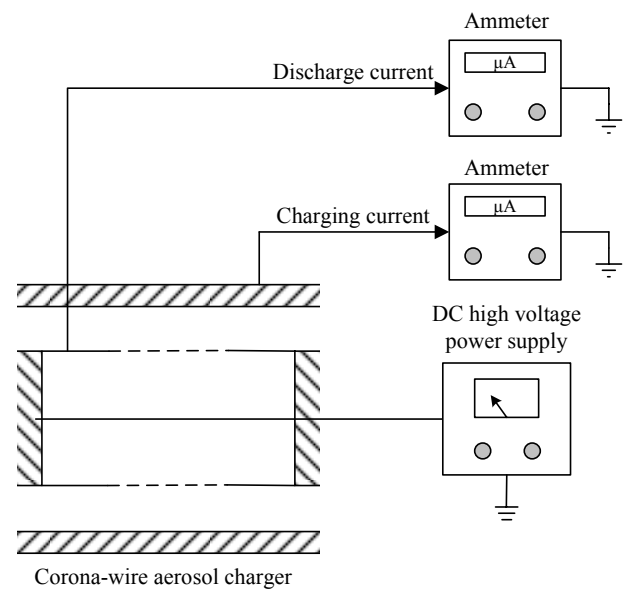

Fig. 3. Experimental setup for the electrostatic discharge characterization of the corona-wire aerosol charger.

consider the ion current density $\left(\mathrm{A} / \mathrm{m}^{2}\right)$ as:

where

$$
j=\rho u_{i o n},
$$

$$
\begin{gathered}
\rho=n_{i o n} e \text { and } \\
u_{i o n}=Z_{i o n} E .
\end{gathered}
$$

In the above, $\rho$ is the space-charge density $\left(\mathrm{kg} / \mathrm{m}^{3}\right), u_{\text {ion }}$ is the ion velocity $(\mathrm{m} / \mathrm{s}), e$ is the elementary charge $(1.61$ $\left.\times 10^{-19} \mathrm{C}\right), Z_{\text {ion }}$ is the electrical mobility of the ions $\left(\mathrm{m}^{2} / \mathrm{V} . \mathrm{s}\right)$, and $E$ is the average electric field inside the discharge and charging zones of the charger $(\mathrm{V} / \mathrm{m})$. Thus, ion current density $\left(\mathrm{A} / \mathrm{m}^{2}\right)$ is given by:

$$
j=n_{\text {ion }} e Z_{\text {ion }} E
$$

where $j=I / A$, with $I$ representing the discharge and charging currents and $A$ representing the inner surface area of the inner and outer electrodes where the discharge and charging currents are collected. Thus, the mean ion number concentration $n_{\text {ion }}$ in the discharge and charging zones of the corona-wire charger in the absence of aerosol particles can be estimated from the discharge and charging currents using the expression [12-13]:

$$
n_{\text {ion }}=\frac{I}{e Z_{i o n} E A} \text {. }
$$

The ion number concentration has units of ions $/ \mathrm{m}^{3}$. The limits of investigated variables are shown in Table 1. For each set of operating conditions, measurements were repeated at least three times.
Table 1. Limits of investigated variables.

\begin{tabular}{c|c}
\hline Variable & Range \\
\hline Corona wire diameter & $300 \mu \mathrm{m}$ \\
Inner electrode diameter & $21 \mathrm{~mm}$ \\
Outer electrode diameter & $35 \mathrm{~mm}$ \\
Corona voltage & $0-10 \mathrm{kV}$ \\
Inner electrode voltage & $0,250 \mathrm{~V}$ \\
Ion generated & Positive ion $(+)$, negative ion $(-)$ \\
Ionized gas & Air \\
Pressure & $1 \mathrm{bar}$ \\
Temperature & $30^{\circ} \mathrm{C}$ \\
\hline
\end{tabular}

\section{Results and Discussion}

The corona discharge current-voltage characteristics of the positive and negative coronas in the discharge and charging zones of the charger, when inner electrode voltage was maintained at $0 \mathrm{VDC}$, are shown in Fig. 4. Both

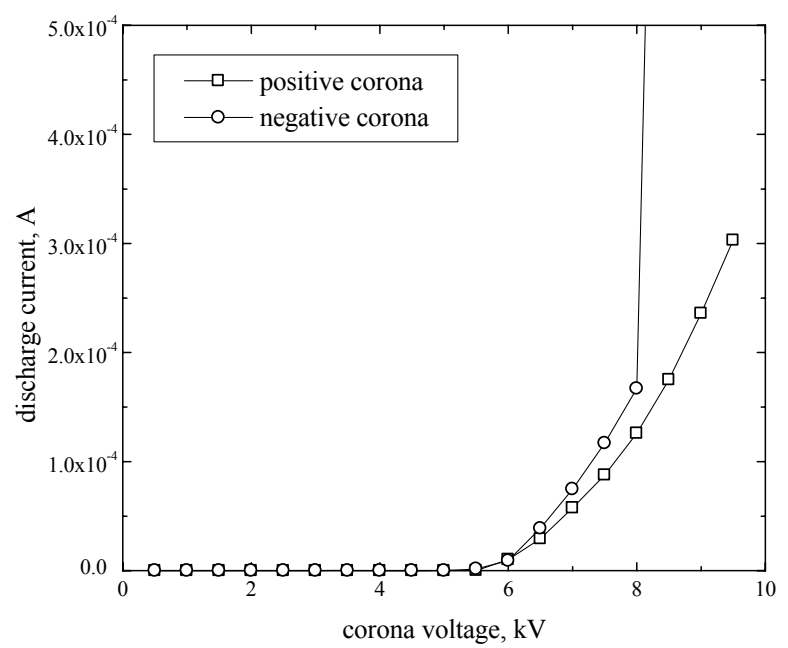

(a)

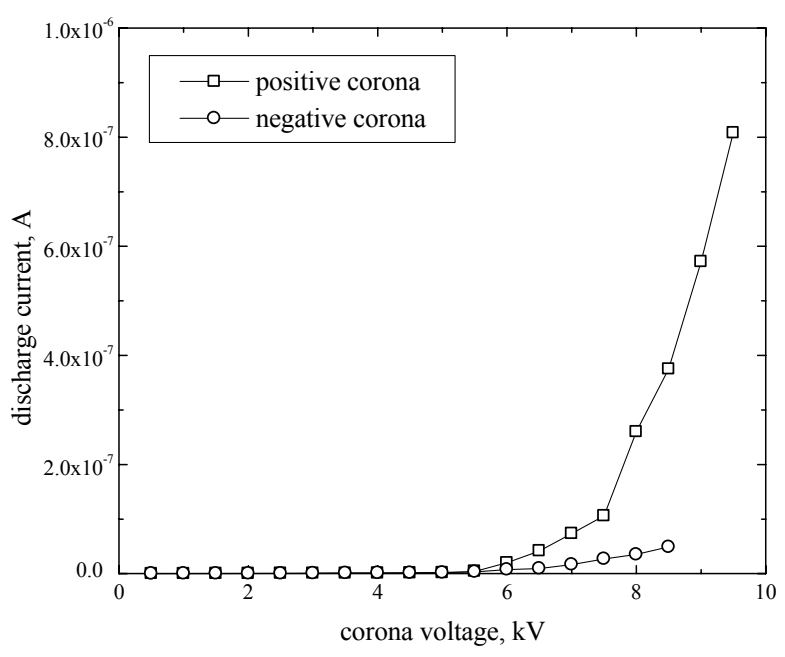

(b)

Fig. 4. Current-voltage characteristics of the charger: (a) discharge zone, and (b) charging zone. 
discharge and charging currents increased monotonically with increasing corona voltage. In the discharge zone, the onset voltage of positive corona was found to be about 5.5 $\mathrm{kV}$ at a current of $1.44 \times 10^{-6} \mathrm{~A}$, while the negative corona was about $5.5 \mathrm{kV}$ at a current of $1.53 \times 10^{-6} \mathrm{~A}$ [Fig. 3(a)]. Compared with positive corona, the magnitude of the discharge currents was markedly higher for the negative corona at the same corona voltage. This was because the negative ions had higher electrical mobility than the positive ions, $Z_{\text {ion }}^{+}=1.15 \times 10^{-4} \mathrm{~m}^{2} / \mathrm{V} \mathrm{s}, Z_{\text {ion }}^{-}=1.425 \times 10^{-4}$ $\mathrm{m}^{2} / \mathrm{V}$ s, respectively, based on the work of Reischl et al. [14]. The spark-over phenomena occurred for the positive corona at voltages larger than $9.5 \mathrm{kV}$, and for negative corona at voltages larger than $8.5 \mathrm{kV}$. Above these values, the current fluctuated in an uncontrollable manner, and no measurement could be made. In the charging zone [Fig. 3 (b)], the onset voltage of both positive and negative coronas was also found to be about $5.5 \mathrm{kV}$ at currents of $3.97 \times 10^{-9}$ and $3.28 \times 10^{-9} \mathrm{~A}$, respectively. A higher voltage rise was observed for negative charge in the discharge zone, whereas the opposite was true for the charging zone. At the same corona voltage, the magnitude of the charging currents for positive corona was slightly higher than that of the negative corona, because negative ions had higher electrical mobility than the positive ions. Therefore, negative ions were more likely to deposit on the perforated inner electrode of the charger due to lost electrostatic. The current in the discharge zone was also about 600 times larger than the charging current. This means that more ions have a tendency to be electrostatically lost on the perforated inner electrode of the charger.

A 250 VDC voltage was applied to the perforated inner electrode of the charger to investigate the ion penetration. The variations of charging current with corona voltage for both positive and negative coronas are shown in Fig. 5. At

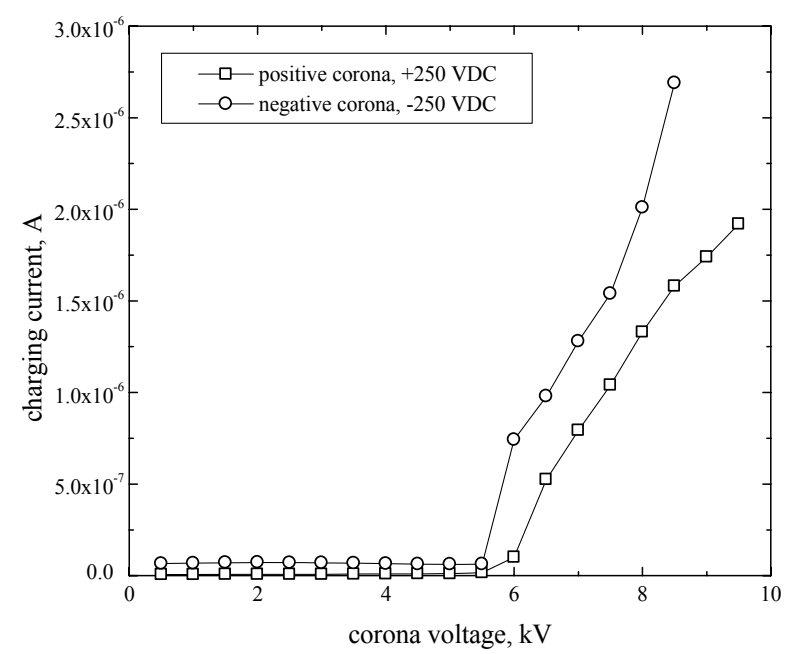

Fig. 5. Variation of charging currents with corona voltage at the perforated inner electrode voltage of 250 VDC. the same corona voltage, the magnitude of the charging currents at the inner electrode voltage of $250 \mathrm{VDC}$ was about 5-100 times larger than the charging currents at the inner electrode voltage of $0 \mathrm{VDC}$. In this case, the negative corona was found to be slightly higher than the positive corona.

The distribution of electric field in the discharge and charging zones of the charger was also investigated. The radial variation of the electric field in the two zones of the charger at different corona voltage, for the inner electrode voltage of 0 and $250 \mathrm{VDC}$, respectively, are shown in Fig. 6. In the case of $0 \mathrm{VDC}$, an increase in radial distance away from the corona wire resulted in marked discrepancy in the electric field strength in both zones. In addition, the electric field strength increased with the corona voltage. In the case of $250 \mathrm{VDC}$, electric field strength appeared to depend on

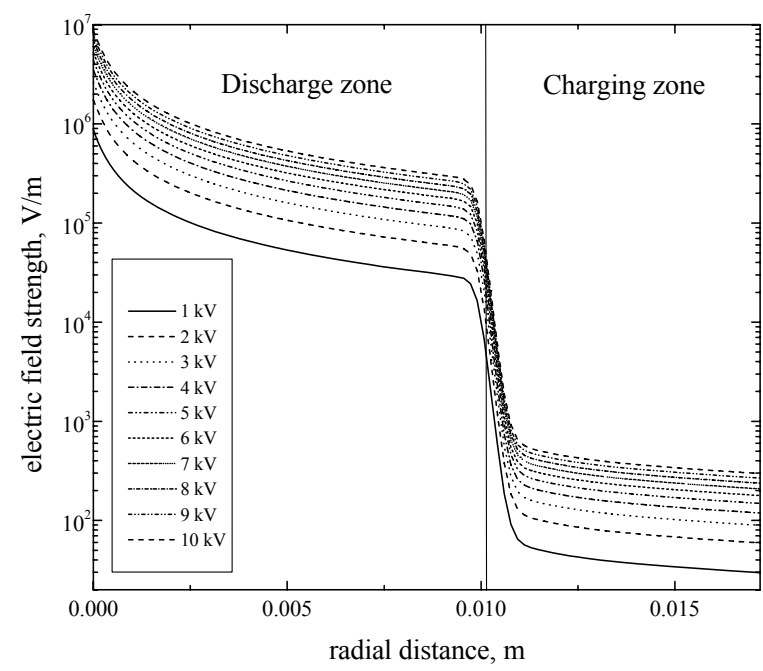

(a)

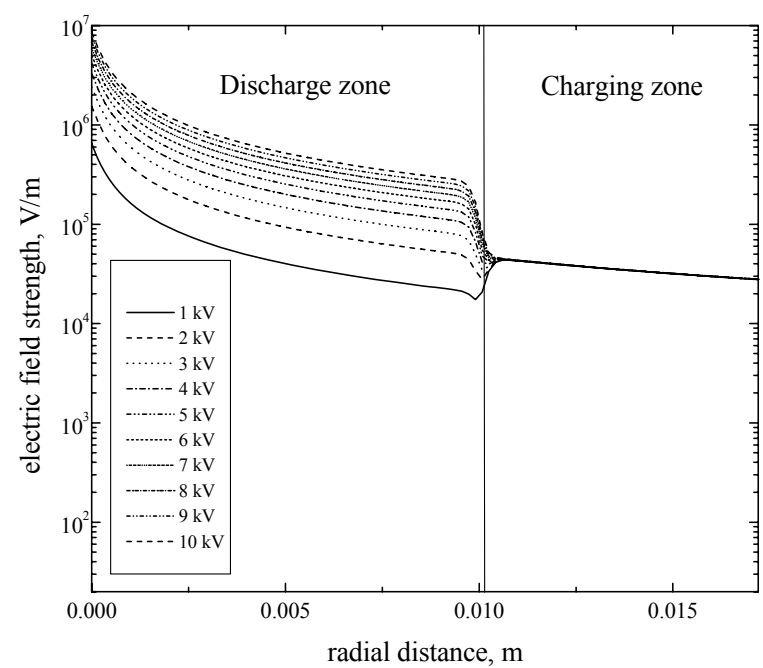

(b)

Fig. 6. Radial variations of the electric field in the two charger regions at (a) $0 \mathrm{VDC}$, and (b) $250 \mathrm{VDC}$. 
corona voltage but only in the discharge zone. The electric field strength in the charging zone practically became constant.

The numerical calculation results of the ion penetration through the perforated inner electrode, at the inner electrode voltage levels of 0 and $250 \mathrm{VDC}$, are shown in Fig. 7. The numerical calculation helped predict the electric field flow lines, on which the ions travelled from the discharge zone to the charging zone within the charger. The number of streamlines passing through the perforated inner electrode would then be proportional to the ion penetration from the discharge zone to the charging zone. Such electric field flow lines can be increased by increasing the inner electrode voltage (Fig. 7). As mentioned in the previous section, the concentrations of ions in the charger can be determined from measured discharge and charging currents because they are approximately proportional. Variations in ion number concentration with corona voltage in the discharge and charging zones of the charger are shown in Fig. 8. As seen in the plot, the ion number concentration in both zones increased with increasing corona voltage.

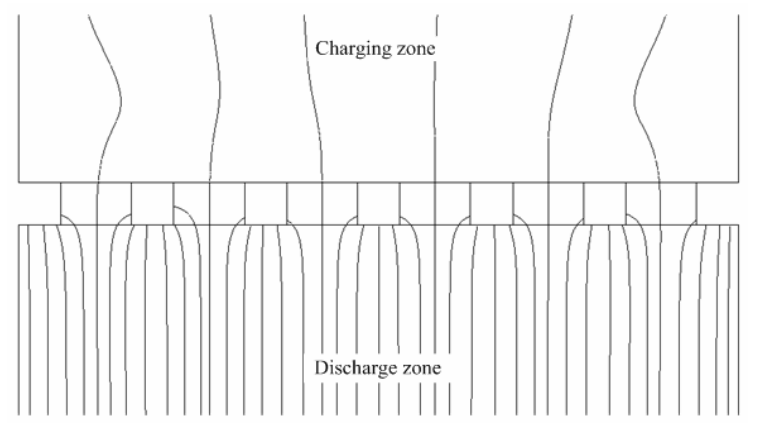

(a)

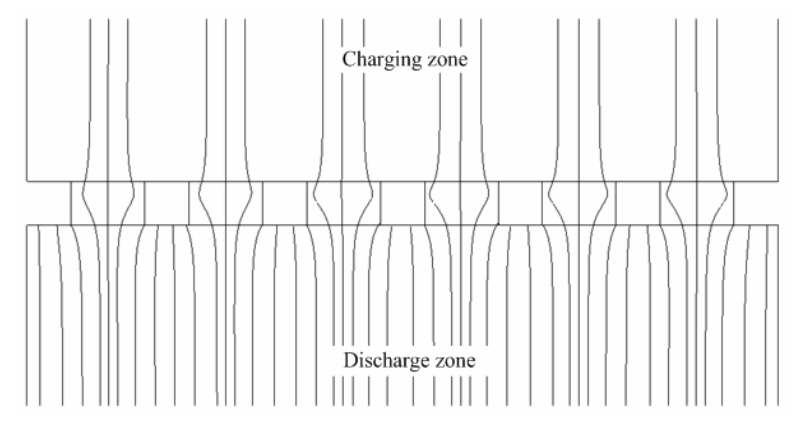

(b)

Fig. 7. Numerical calculation of the ion penetration through the perforated inner electrode: (a) $0 \mathrm{VDC}$, and (b) 250 VDC.

The ion number concentration in the discharge zone[Fig. $8(\mathrm{a})$ ] was found to be in the range of approximately $5.0 \times$ $10^{10}$ to $1.24 \times 10^{16}$ ions $/ \mathrm{m}^{3}$. The number concentration of the negative ions was generally larger than that of the positive ions, in a range well above the corona onset. In addition, Fig. 8(b) shows the variation in ion number concentration with corona voltage in the charging zone of the charger at different inner electrode voltage. At 0 VDC inner electrode voltage, the ion number concentration in the charging zone was in the range of approximately $1.3 \times$ $10^{13}$ to $2 \times 10^{16}$ ions $/ \mathrm{m}^{3}$. At $250 \mathrm{VDC}$, the inner electrode voltage was in the range of approximately $4.5 \times 10^{12}$ to 1.5 $\times 10^{15} \mathrm{ions} / \mathrm{m}^{3}$. A difference of the initial ion number concentration under onset corona voltages was expected due to the difference in the electrical mobilities of the ions. In turn, this corresponded to ion penetration. The electrical mobility of the negative ions was about two times higher than that of the positive ions. Thus, the negative ions had higher penetration than positive ions at the initial corona voltage.

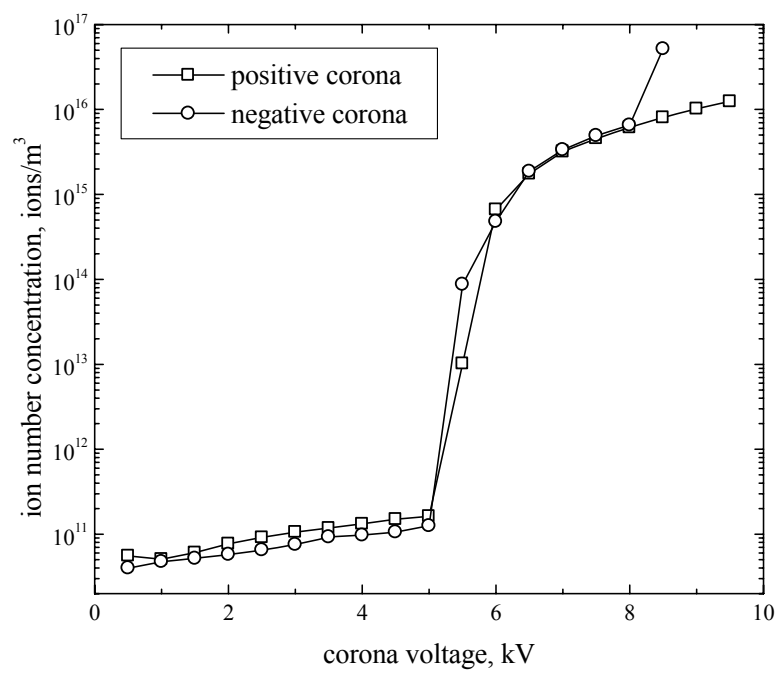

(a)

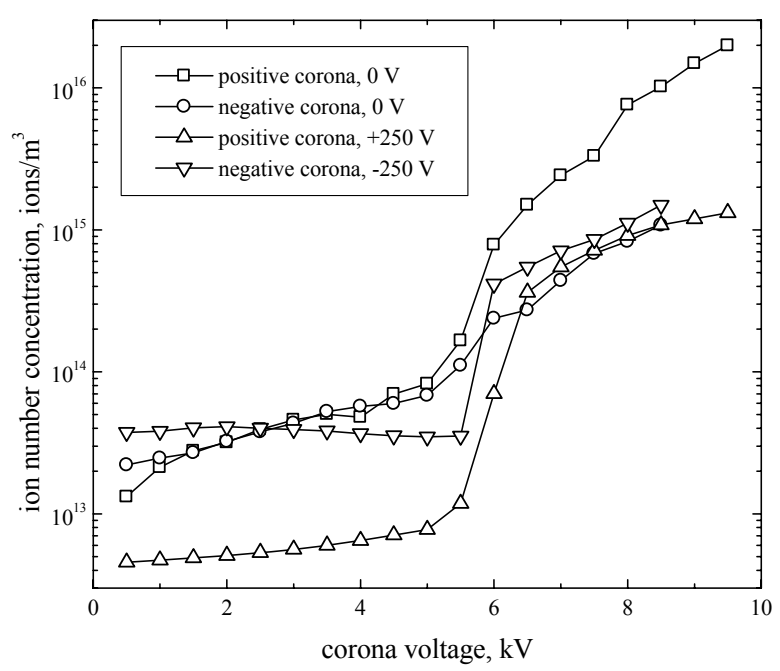

(b)

Fig. 8. Variations in ion number concentrations with corona voltage in the charger: (a) discharge zone, and (b) charging zone. 


\section{Conclusions}

In the present work, the electrostatic discharge characteristics of a unipolar diffusion corona-wire charger for aerosol particles, with simple design and fabrication, have been evaluated. The charging current and ion concentration in the charging zone increased monotonically with corona voltage. The negative corona has been found to have a higher current than the positive corona. At the same corona voltage, the current in the discharge zone was about 600 times larger than the charging current.

The ion number concentrations in the discharge and charging zones have been found to be in the range of approximately $5.0 \times 10^{10}$ to $1.24 \times 10^{16}$, and $4.5 \times 10^{12}$ to 2 $\times 10^{16}$ ions $/ \mathrm{m}^{3}$, respectively. A numerical model used to estimate the ion penetration through the inner electrode of the charger also showed a similar pattern with those of the experimental measurements. However, the experimental results are more consistent with those of the model.

\section{Acknowledgment}

This work was supported by the National Science and Technology Development Agency: Northern Network, Thailand, under Contract no. NT-RD-2552-07.

\section{References}

[1] P. Intra and N. Tippayawong, "Progress in unipolar corona discharger designs for airborne particle charging: A literature review", Journal of Electrostatics, Vol. 67, No. 4, pp. 605-615, 2009.

[2] P. Buscher, A. Schmidt-Ott, and A. Wiedensohler, "Performance of a unipolar "Square Wave" diffusion charger with variable nt-product", Journal of Aerosol Science, Vol. 25, No. 4, pp. 651-663, 1980.

[3] F. E. Kruis and H. Fissan, "Nanoparticle charging in a twin Hewitt charger", Journal of Nanoparticle Research, Vol. 3, pp. 39-50, 2001.

[4] G. Biskos, K. Reavell and N. Collings, "Electrostatic characterization of corona-wire aerosol charges", Journal of Electrostatics, Vol. 63, pp. 69-82, 2005.

[5] A. Medved, F. Dorman, S. L. Kaufman and A. Pocher, "A new corona-based charger for aerosol particles", Journal of Aerosol Science, Vol. 31, pp. s616-s617, 2000.

[6] A. Marquard, M. Kasper, J. Meyer, and G. Kasper, "Nanoparticle charging efficiencies and related charging conditions in a wire-tube ESP at DC energization", Journal of Electrostatics, Vol. 63, pp. 693-698, 2005.

[7] D. Park, M. An, and J. Hwang, "Development and performance test of a unipolar diffusion charger for real-time measurements of submicron aerosol particles having a log-normal size distribution", Journal of Aerosol Science, Vol. 38, No. 4, pp. 420430, 2007.

[8] B. Y. H. Liu and D. Y. H. Pui, "On the performance of the electrical aerosol analyzer", Journal of Aerosol Science, Vol. 6, pp. 249-264, 1975.

[9] G. W. Hewitt, "The charging of small particles for electrostatic precipitation", AIEE Transactions, Vol. 76, pp. $300-306,1957$.

[10] Y. J. Lee, H. T. Kim and K. W. Lee, "Development of monitoring technology for airborne particulate matter", Environmental Monitoring and Assessment, Vol. 70, pp. 3-20, 2001.

[11] CFDRC Manual, CFDRC 2004, User's Guide, 2004.

[12] P. Itra and N. Tippayawong, "Approach to characterization of a diode type corona charger for aerosol size measurement", KIEE International Transactions on Electrophysics \& Applications, Vol. 5-C, No. 5, pp. 196-203, 2005.

[13] P. Intra and N. Tippayawong, "Comparative study on electrical discharge and operation characteristics of needle and wire-cylinder corona chargers", Journal of Electrical Engineering \& Technology, Vol. 1, No. 4, pp. 520-527, 2006.

[14] G.P. Reischl, J.M. Makela, R. Harch, and J. Necid, Bipolar charging of ultrafine particles in the size range below $10 \mathrm{~nm}$, Journal of Aerosol Science, Vol. 27, pp. 931-949, 1996.

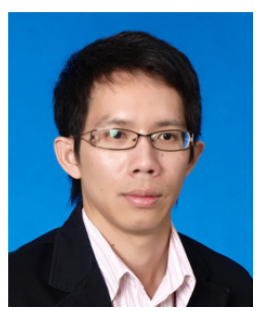

Panich Intra received his BS. Tech. Ed. degree in Electrical Engineering from the Rajamangala Lanna University of Technology, Thailand in 2001. He then received his M. Eng. degree in Energy Engineering and his Ph.D. degree in Mechanical Engineering in 2003 and 2006, respectively, from Chiang Mai University, Thailand. $\mathrm{He}$ is currently a Lecturer in the College of Integrated Science and Technology, Rajamangala University of Technology Lanna, Thailand. His research interests include detection and measurement of nanometer-sized aerosol particles, as well as electrostatic precipitation.

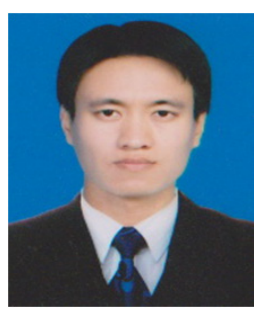

Artit Yawootti received his BS. Tech. Ed. and M. Eng. degrees in Electrical Engineering from King Mongkut's University of Technology Thonburi, Thailand in 2000 and 2006, respectively. $\mathrm{He}$ is currently a doctoral student in Mechanical Engineering at Chiang Mai University, Thailand. His interests include aerosol measurement technology, control, and instrumentation. 


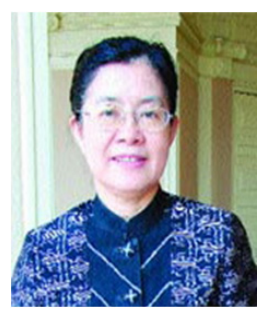

Usanee Vinitketkumnuen received her Ph.D. degree in Biochemistry from the University of Tokyo, Japan in 1991. She is currently a Professor at the Faculty of Medicine, Chiang Mai University. Her research interests are biochemical toxicology and particulate matter measurement.

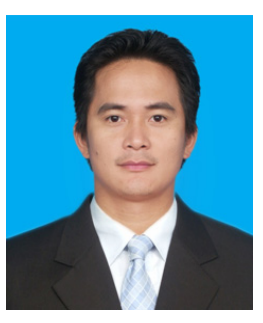

Nakorn Tippayawong received his B.Eng. and Ph.D. degrees in Mechanical Engineering from Imperial College, UK in 1996 and 2000, respectively. $\mathrm{He}$ is currently an Associate Professor at the Department of Mechanical Engineering, Chiang Mai University. His research interests include HV applications in aerosol system and renewable energy. 